\title{
Avaliação de níveis e fontes de proteína na alimentação de leitões na fase inicial de crescimento
}

\author{
Otto Mack Junqueira ${ }^{1}$, Liliam Zambrana Toledo Silz² ${ }^{2}$ Lúcio Francelino Araújo ${ }^{3}$, Adriana \\ Aparecida Pereira ${ }^{2}$, Antônio Carlos de Laurentiz ${ }^{4}$, Rosemeire da Silva Filardi ${ }^{4}$
}

\footnotetext{
${ }^{1}$ Departamento de Zootecnia - FCAVJ/UNESP.

2 Doutoranda do Departamento de Zootecnia - FCAVJ/UNESP.

${ }^{3}$ Departamento de Zootecnia - FZEA/UNESP.

${ }^{4}$ Departamento de Zootecnia - FEIS/UNESP.
}

RESUMO - Um experimento foi conduzido para comparar diversos níveis e fontes protéicas utilizados em rações sobre o desempenho, a morfometria intestinal e a relação peso de pâncreas/peso de carcaça de leitões de 36 a 70 dias de idade. Foram utilizados 96 leitões desmamados distribuídos em delineamento de blocos ao acaso com seis tratamentos e quatro repetições de quatro animais. Avaliaram-se seis fontes protéicas (tratamentos): leite em pó desnatado ( 8,80 e 12,00\%); isolado protéico de soja (3,20 e 4,50\%); farinha de peixe (5,00\%); e levedura seca (10,00\%). As dietas, isoenergéticas e isoprotéicas, não afetaram o ganho de peso e a conversão alimentar dos animais, contudo, os animais que receberam a dieta contendo leite em pó desnatado apresentaram maior consumo no período de 56 a 63 dias de idade. Não houve efeito significativo das fontes protéicas sobre a altura de vilos, a profundidade de cripta e a relação peso do pâncreas/peso corporal. As fontes protéicas estudadas e os níveis utilizados nas dietas não influenciaram o desempenho, a morfologia intestinal e a relação peso de pâncreas/ peso de carcaça em leitões de 36 a 70 dias de idade.

Palavras-chave: desempenho, farinha de peixe, isolado protéico de soja, leite em pó desnatado, levedura seca, morfologia intestinal

\section{Evaluation of levels and protein sources in diets of piglets in the initial growth phase}

\begin{abstract}
An experiment was conducted to compare different levels and sources of protein on performance, intestinal morphology and pancreas weight/carcass weight ratio in the diets of piglets from 36 to 70 days old. A total of 96 piglets was allotted to a randomized experimental block design in six diets, with different levels and protein sources, four replicates of four animals per experimental unit. The levels and the protein sources evaluated were: dry skim milk (8.80 and $12.00 \%)$, isolated soybean protein $(3.20$ and $4.50 \%)$, fish meal $(5.00 \%)$ and dry yeast $(10.00 \%)$. The diets were isoenergetics and isoproteics. The diets did not affect weight gain and feed conversion of the animals, however, the pigs that were fed diet with dry skim milk showed higher feed intake from 56 to 63 days old. There was no effect of protein sources on villus height, crypt depth and pancreas weight/carcass weight ratio. The levels and protein sources in the diet did not affect performance, intestinal morphology and pancreas weight/carcass ratio of the piglets from 36 to 70 days old.
\end{abstract}

Key Words: dry skim milk, dry yeast, fish meal, intestinal morphology, isolated soybean protein, performance

\section{Introdução}

Atualmente a tecnologia empregada na produção de suínos visa diminuir a idade de desmame a fim de aumentar a produtividade das porcas, o que resulta em aumento de leitões produzidos por porca/ano. O êxito desta prática requer, no entanto, a utilização de dietas diferenciadas, contendo ingredientes com alta digestibilidade para esse período tão crítico da vida do leitão, uma vez que o acúmulo de situações estressantes é inevitável e deixa o animal suscetível a distúrbios gastroentéricos.

Visando diminuir o impacto causado pelo desmame, têm-se utilizado proteínas lácteas em dietas iniciais para contornar o problema da adição de grandes quantidades de farelo de soja em dietas para esta faixa etária, as quais desencadeiam diarréias profusas, que levam a desidratação e redução do desempenho, além de aumento da taxa de mortalidade. No entanto, a utilização de proteínas 
lácteas de derivados lácteos na nutrição animal compete com a nutrição humana, eleva o preço de mercado deste produto para o consumo humano.

O leite em pó desnatado tem sido considerado essencial em dietas para leitões desmamados precocemente. Esse alimento fornece proteína de alta qualidade e também é fonte de lactose para o leitão, no entanto, pesquisas recentes têm comprovado que o leite em pó desnatado pode ser substituído por fontes protéicas de menor custo sem diminuir o desempenho dos animais. A farinha de peixe é amplamente utilizada como fonte protéica de alta qualidade e produtos de soja processados têm sido uma alternativa para o uso em dietas para leitões desmamados (Thacker, 1999).

Entre as fontes alternativas, destaca-se o isolado e o concentrado protéico de soja. Esses produtos causam diminuição da reação de hipersensibilidade transitória causada pelo farelo de soja, o que se comprova pelo aumento no tamanho das vilosidades intestinais, pela melhora na digestibilidade e pelo maior ganho de peso em comparação ao obtido com farelo de soja (Robles, 1993).

Alguns pesquisadores têm avaliado a utilização de farinha de peixe em dietas para leitões e verificado resposta consideravelmente variável à farinha de peixe, o que pode estar relacionado à variação na qualidade das farinhas de peixe. O valor final da farinha de peixe como fonte de proteína depende de sua qualidade e de seu efeito no balanço total de aminoácidos total da dieta (Stoner et al., 1990).

Outro ingrediente utilizado como fonte protéica é a levedura seca. Araújo et al. (2006), trabalhando com diferentes níveis de levedura seca na dieta de leitões desmamados, não observaram efeitos negativos da utilização deste produto na dieta dos animais.

As marcantes e abruptas respostas morfológicas ao desmame no intestino delgado de leitões, caracterizado pela transformação de uma densa população de vilos semelhantes a dedos para uma superfície em formato de língua (Nabuurs, 1995), pode indicar reações críticas da capacidade digestiva do leitão jovem a ingredientes utilizados na fase inicial. Durante o período pós-desmame, a área de superfície do vilo do intestino delgado é significativamente alterada, pelo menos durante o período de 7 a 14 dias pósdesmame. O encurtamento da área de superfície do vilo do intestino delgado poderia predispor os leitões desmamados à má absorção, à desidratação e diarréia e a condições entéricas infecciosas que freqüentemente são encontradas em granjas comerciais.

Em leitões de 21 dias de idade, o pâncreas representa $1,39 \%$ do peso corporal. O desenvolvimento desse órgão é importante ao desmame porque suas enzimas apresentam importante função na digestão de dietas pós-desmame, as quais contêm amido e proteínas vegetais. A variação dessas atividades enzimáticas (coeficiente de variação de 48,80\% para quimiotripsina e $62,90 \%$ para amilase aos 21 dias de idade) foi associada ao ganho de peso, portanto, leitões que crescem mais, ou mais pesados, poderiam responder mais eficientemente a mudanças nas dietas ao desmame por terem o sistema digestivo mais desenvolvido.

Este trabalho foi realizado com o objetivo de avaliar o desempenho, a morfometria intestinal e a relação peso de pâncreas/peso de carcaça de leitões dos 36 aos 70 dias de idade alimentados com dietas com diferentes níveis e fontes protéicas.

\section{Material e Métodos}

Em um período experimental de 34 dias, foram utilizados 96 leitões (48 machos e 48 fêmeas), dos 36 aos 70 dias de idade, com peso inicial de $8,49 \pm 0,37 \mathrm{~kg}$, distribuídos em delineamento experimental de blocos casualizados, com seis tratamentos e quatro repetições (blocos) de quatro leitões (dois machos e duas fêmeas), totalizando 16 animais por tratamento.

Os tratamentos consistiram de dietas isoprotéicas e isoenergéticas contendo diversos níveis e fontes protéicas: leite em pó desnatado $(8,80 \%$ e $12,00 \%)$; isolado protéico de soja $(3,20 \%$ e $4,50 \%)$; farinha de peixe $(5,00 \%)$; e levedura seca $(10,00 \%)$ (Tabela 1$)$.

Antes de cada período experimental, todos os leitões receberam a mesma dieta pré-experimental (ração comercial) até os 35 dias de idade. As dietas e a água foram fornecidas à vontade e os animais e as dietas experimentais foram pesados semanalmente.

Ao término do período experimental, três animais de cada tratamento, com peso mais próximo da média, foram abatidos por meio de secção da veia jugular, para coleta de pâncreas e de fragmentos do intestino delgado e para a pesagem das carcaças. Após o abate dos animais, fragmentos de intestino delgado e os pâncreas foram retirados e pesados.

Amostras de aproximadamente $1 \mathrm{~cm}$ de comprimento foram coletadas da porção proximal do duodeno de cada animal. Os fragmentos foram abertos pela borda mesentérica, lavados, estendidos pela túnica serosa e fixados em solução de Bouin, em frascos de vidro identificados com o número de cada animal, para posterior processamento.

As amostras foram mantidas por 24 horas em solução fixadora de Bouin e, em seguida, foram lavadas em álcool etílico a 70\%. Posteriormente, foram desidratadas em série crescente de alcoóis. Após a desidratação, foram recorta- 
Tabela 1 - Composição centesimal das dietas experimentais

\begin{tabular}{|c|c|c|c|c|c|c|}
\hline Ingrediente & \multicolumn{6}{|c|}{ Fonte de protéina* } \\
\hline Milho & 68,35 & 61,74 & 67,40 & 67,62 & 67,99 & 68,95 \\
\hline Leite desnatado & 12,00 & - & - & - & - & 8,80 \\
\hline Isolado protéico de soja & - & - & 4,50 & - & 3,20 & - \\
\hline Levedura seca & - & 10,00 & - & - & - & - \\
\hline Óleo de soja & - & 0,87 & 1,45 & 0,84 & 1,39 & 0,29 \\
\hline Protenose & 3,00 & 3,00 & 3,00 & 3,00 & 3,00 & 3,00 \\
\hline Calcário & 0,86 & 0,97 & 0,91 & 0,56 & 0,92 & 0,85 \\
\hline Fosfato bicálcico & 1,12 & 1,37 & 1,52 & 0,82 & 1,49 & 1,20 \\
\hline Lisina & 0,21 & 0,18 & 0,27 & 0,20 & 0,27 & 0,22 \\
\hline Metionina & - & 0,01 & 0,02 & - & 0,02 & - \\
\hline Energia digestível (kcal/kg) & 3.440 & 3.440 & 3.440 & 3.440 & 3.440 & 3.440 \\
\hline Proteína bruta $(\%)$ & 18,20 & 18,20 & 18,20 & 18,20 & 18,20 & 18,20 \\
\hline Fibra bruta $(\%)$ & 2,17 & 2,15 & 2,16 & 2,34 & 2,33 & 2,32 \\
\hline Lactose $(\%)$ & 6,12 & 6,12 & 6,12 & 4,49 & 4,49 & 4,49 \\
\hline Cálcio $(\%)$ & 0,82 & 0,82 & 0,82 & 0,82 & 0,82 & 0,82 \\
\hline Fósforo disponível (\%) & 0,40 & 0,40 & 0,40 & 0,40 & 0,40 & 0,40 \\
\hline Sódio $(\%)$ & 0,21 & 0,21 & 0,21 & 0,21 & 0,21 & 0,21 \\
\hline Lisina $(\%)$ & 1,10 & 1,10 & 1,10 & 1,10 & 1,10 & 1,10 \\
\hline Metionina $(\%)$ & 0,35 & 0,35 & 0,35 & 0,35 & 0,35 & 0,35 \\
\hline Metionina + cistina $(\%)$ & 0,65 & 0,65 & 0,65 & 0,65 & 0,65 & 0,65 \\
\hline Triptofano $(\%)$ & 0,21 & 0,21 & 0,21 & 0,21 & 0,21 & 0,21 \\
\hline Treonina $(\%)$ & 0,73 & 0,73 & 0,73 & 0,73 & 0,73 & 0,73 \\
\hline
\end{tabular}

das, diafanizadas em benzol e incluídas em parafina, para os cortes longitudinais da mucosa intestinal.

Em cada lâmina histológica, foram colocados seis cortes semi-seriados com $5 \mathrm{~mm}$ de espessura, de modo que, entre um corte e o subseqüente, foram desprezados cortes cortes. Os cortes foram corados segundo as técnicas da hematoxilina de Harris-eosina.

Com as lâminas prontas, foram feitas 30 medidas de altura de vilosidades (micra) e 30 de profundidade de cripta (micra) para o segmento do duodeno coletado.

As medidas de altura de vilosidades foram tomadas a partir da região basal, que coincide com a porção superior das criptas, percorrendo-a longitudinalmente até seu ápice e as criptas, da sua base até a região de transição cripta-vilo.

A análise morfométrica do intestino delgado foi realizada em um sistema analisador de imagens da Kontron Elektronik(Vídeo Plan) por meio de microscopia de luz, com aumento de 230 vezes. Os parâmetros avaliados foram: ganho de peso, consumo de ração, conversão alimentar, altura de vilos, profundidade de cripta e relação entre peso de pâncreas e peso de carcaça.
As análises estatísticas dos dados obtidos foram realizadas por meio do programa SAS (1996). Os tratamentos avaliados foram comparados pelo teste Tukey a $5 \%$ probabilidade (Steel \& Torrie, 1980).

\section{Resultados e Discussão}

Não foram verificadas diferenças significativas $(\mathrm{P}>0,05)$ para o ganho de peso (Tabela 2) entre as fontes protéicas avaliadas. Entretanto, houve tendência de melhora no ganho de peso quando os leitões foram alimentados com leite em pó desnatado. No entanto, naqueles alimentados com as dietas contendo farinha de peixe, isolado protéico de soja $(3,20 \%)$ e leite em pó desnatado $(8,80 \%)$, a utilização de isolado protéico de soja promoveu menor ganho de peso.

De modo geral, a utilização de isolado protéico de soja e levedura seca nas dietas de leitões nesta faixa etária promoveu resultados muito semelhantes, assim como os valores de ganho de peso dos leitões alimentados com leite em pó desnatado e farinha de peixe foram semelhantes entre si. O aumento de $8,80 \%$ para $12,00 \%$ de leite em pó 
Tabela 2 - Ganho de peso $(\mathrm{kg})$ de leitões alimentados com dietas contendo diferentes níveis e fontes protéicas no período de 36 a 70 dias

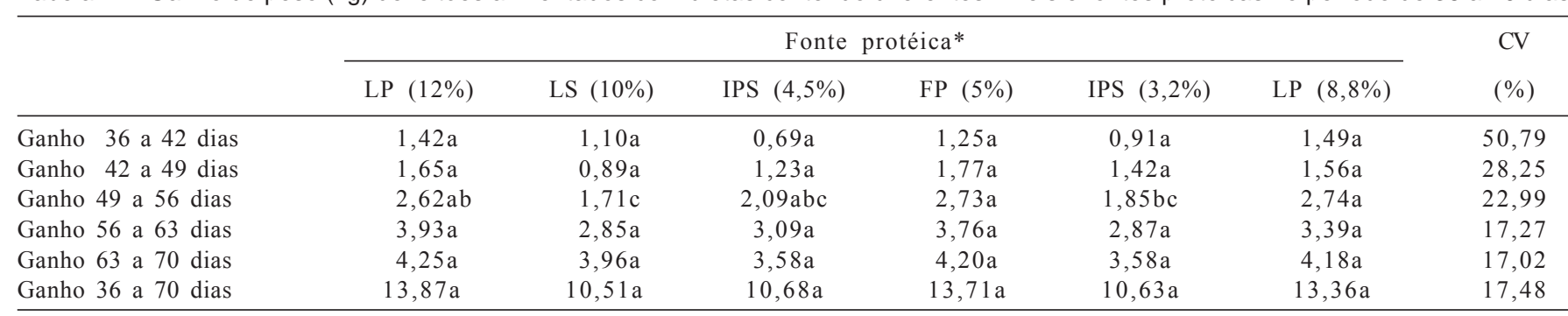

* LP - leite em pó desnatado; LS - levedura seca; IPS - isolado protéico de soja; FP - farinha de peixe.

Médias seguidas de mesma letra minúscula (linha) dentro de cada período analisado, não diferem significativamente no nível de $5 \%$ pelo teste Tukey.

desnatado ou a inclusão de $4,50 \%$ ou $3,20 \%$ de isolado protéico de soja não melhorou o ganho de peso $(\mathrm{P}>0,05)$ dos animais.

Entre todos os períodos estudados, apenas na fase de 49 a 56 dias de idade, foram encontradas diferenças entre as fontes protéicas $(\mathrm{P}<0,05)$. Os melhores resultados de ganho de peso foram obtidos nos animais alimentados com as rações contendo leite em pó desnatado $(8,80 \%)$, isolado protéico de soja $(3,20$ e $4,50 \%)$ e farinha de peixe.

Utilizando farinha de peixe, isolado protéico de soja e caseína para leitões dos 7 aos 28 dias de idade, Leibholz (1982) encontrou valores superiores para ganho de peso em leitões alimentados com caseína e farinha de peixe em comparação aos alimentados com isolado protéico de soja. Resultados semelhantes foram reportados por Cinq-Mars et al. (1986), que observaram aumento de ganho de peso em leitões de diversas idades alimentados com proteína láctea e farinha de peixe.

Resultados semelhantes aos obtidos neste estudo foram encontrados por Deboer et al. (1988) com o fornecimento das mesmas fontes protéicas para leitões de várias idades. Esta variação na resposta ao uso de farinha de peixe pode estar relacionada à qualidade do produto utilizado, e não ao seu valor final como fonte de proteína (Stoner et al., 1990).

O maior consumo de ração $(\mathrm{P}<0,05)$ foi observado para os animais alimentados com a dieta contendo leite em pó desnatado (12,00 e 8,80\%) e farinha de peixe. Os animais que receberam $12 \%$ de leite em pó desnatado tiveram consumo 8,67 e $6,28 \%$ maior que o daqueles que receberam farinha de peixe e $8,80 \%$ de leite em pó desnatado, respectivamente (Tabela 3).

As dietas contendo isolado protéico de soja e levedura seca proporcionaram aos leitões menor consumo de ração em comparação aos demais alimentos avaliados. Araújo et al. (2006), no entanto, relataram que a utilização de até $15,00 \%$ de levedura desidratada em rações para suínos na fase inicial não afeta o consumo de ração.
Neste estudo, leitões alimentados com as dietas contendo farinha de peixe, isolado protéico de soja $(3,20 \%) \mathrm{e}$ leite em pó desnatado $(8,80 \%)$ consumiram quantidades semelhantes de ração.

Houve diferença significativa $(\mathrm{P}<0,05)$ entre as fontes protéicas no período de 56 a 63 dias de idade, quando os animais alimentados com as dietas contendo leite em pó desnatado apresentaram maior ingestão de alimento. Neste mesmo período, houve redução de aproximadamente $28,00 \%$ no consumo de ração pelos leitões alimentados com isolado protéico de soja ( 3,20 e 4,50\%) em comparação ao leite em pó desnatado.

De forma semelhante, Junqueira et al. (2004), ao verificarem a substituição do leite em pó desnatado pelo isolado protéico de soja em dietas para leitões desmamados, constataram que o consumo de ração diminuiu de acordo com o aumento no nível de substituição da proteína láctea pela proteína de soja. Esses autores salientaram que a inclusão de isolado protéico de soja em nível superior a 3\% da dieta reduz significativamente o consumo de ração no período de 21 a 35 dias de idade dos leitões.

Não houve diferença significativa $(\mathrm{P}>0,05)$ entre as fontes de proteína sobre a conversão alimentar em todos os períodos avaliados (Tabela 4). A tendência de piora observada no ganho de peso no período de 36 a 70 dias de idade para as dietas contendo isolado protéico de soja e levedura seca foi acompanhada de piora significativa no consumo, o que pode ter colaborado para manter os valores médios de conversão alimentar entre todas as dietas semelhantes.

Bertol et al. (2000) avaliaram a inclusão de leite em pó desnatado e proteína concentrada de soja na dieta de leitões no período de 1 a 14 dias pós-desmame e não encontraram efeitos destas fontes protéicas sobre a conversão alimentar dos animais.

Leibholz(1982), por sua vez, observou piora na conversão alimentar em leitões alimentados com isolado protéico de soja e farelo de soja em comparação a leitões alimentados 
Tabela 3 - Consumo de ração $(\mathrm{kg})$ de leitões alimentados com dietas contendo diferentes níveis e fontes protéicas no período de 36 a 70 dias

\begin{tabular}{lccccccc}
\hline & \multicolumn{7}{c}{ Fonte protéica* } \\
\cline { 2 - 5 } & LP (12\%) & LS (10\%) & IPS $(4,5 \%)$ & FP (5\%) & IPS $(3,2 \%)$ & LP $(8,8 \%)$ \\
\hline Consumo 36 a 42 dias & $2,45 \mathrm{a}$ & $2,03 \mathrm{a}$ & $2,00 \mathrm{a}$ & $2,21 \mathrm{a}$ & $2,00 \mathrm{a}$ & $2,47 \mathrm{a}$ \\
Consumo 42 a 49 dias & $3,05 \mathrm{a}$ & $2,34 \mathrm{a}$ & $2,39 \mathrm{a}$ & $3,23 \mathrm{a}$ & $2,48 \mathrm{a}$ & $3,06 \mathrm{a}$ & 14,03 \\
Consumo 49 a 56 dias & $5,21 \mathrm{a}$ & $3,48 \mathrm{a}$ & $3,77 \mathrm{a}$ & $4,65 \mathrm{a}$ & $3,59 \mathrm{a}$ & $4,68 \mathrm{a}$ & 20,34 \\
Consumo 56 a 63 dias & $6,18 \mathrm{a}$ & $4,63 \mathrm{bc}$ & $4,67 \mathrm{bc}$ & $4,99 \mathrm{bc}$ & $4,41 \mathrm{c}$ & $5,52 \mathrm{ab}$ & 12,71 \\
Consumo 63 a 70 dias & $8,24 \mathrm{a}$ & $6,78 \mathrm{a}$ & $6,93 \mathrm{a}$ & $7,89 \mathrm{a}$ & $6,75 \mathrm{a}$ & $7,84 \mathrm{a}$ & 14,22 \\
Consumo 36 a 70 dias & $25,14 \mathrm{a}$ & $19,26 \mathrm{~b}$ & $19,75 \mathrm{~b}$ & $22,96 \mathrm{ab}$ & $19,23 \mathrm{~b}$ & $23,56 \mathrm{ab}$ & 13,47 \\
\hline
\end{tabular}

* LP - leite em pó desnatado; LS - levedura seca; IPS - isolado protéico de soja; FP - farinha de peixe.

Médias seguidas de mesma letra minúscula (linha) dentro de cada período analisado, não diferem significativamente a $5 \%$ pelo teste Tukey.

Tabela 4 - Conversão alimentar $(\mathrm{kg} / \mathrm{kg})$ de leitões alimentados com dietas contendo diferentes níveis e fontes protéicas no período de 36 a 70 dias de idade

\begin{tabular}{|c|c|c|c|c|c|c|c|}
\hline & \multicolumn{6}{|c|}{ Fonte protéica* } & $\begin{array}{l}\mathrm{CV} \\
(\%)\end{array}$ \\
\hline Conversão 36 a 42 dias & $1,73 \mathrm{a}$ & $1,85 \mathrm{a}$ & $2,88 \mathrm{a}$ & $1,78 \mathrm{a}$ & $2,20 \mathrm{a}$ & $1,66 \mathrm{a}$ & 54,39 \\
\hline Conversão 49 a 56 dias & $1,99 \mathrm{a}$ & $2,04 \mathrm{a}$ & $1,86 \mathrm{a}$ & $1,70 \mathrm{a}$ & $1,95 \mathrm{a}$ & $1,71 \mathrm{a}$ & 24,69 \\
\hline Conversão 56 a 63 dias & $1,58 \mathrm{a}$ & $1,63 \mathrm{a}$ & $1,51 \mathrm{a}$ & $1,33 \mathrm{a}$ & $1,54 \mathrm{a}$ & $1,63 \mathrm{a}$ & 15,92 \\
\hline Conversão 63 a 70 dias & $1,94 \mathrm{a}$ & $1,71 \mathrm{a}$ & $1,93 \mathrm{a}$ & $1,88 \mathrm{a}$ & $1,89 \mathrm{a}$ & $1,87 \mathrm{a}$ & 8,11 \\
\hline
\end{tabular}

* LP - leite em pó desnatado; LS - levedura seca; IPS - isolado protéico de soja; FP - farinha de peixe.

Médias seguidas de mesma letra minúscula (linha) dentro de cada período analisado, não diferem significativamente a $5 \%$ pelo teste Tukey.

com leite em pó desnatado e farinha de peixe. O mesmo foi observado por Moura \& Fowler (1985), uma vez que leitões alimentados com dietas contendo leite em pó desnatado e farinha de peixe apresentaram desempenho melhor que o daqueles alimentados com dietas sem estes dois ingredientes e com $30,5 \%$ de farelo de soja.

Não foram constatadas diferenças significativas $(\mathrm{P}>0,05)$ para a morfologia intestinal dos animais entre as fontes protéicas estudadas (Tabela 5). A resposta de desempenho dos animais obtida para as diversas fontes de proteína está de acordo com os resultados de profundidade de cripta e altura de vilosidade, uma vez, que tanto o desempenho como a morfologia intestinal mantiveram-se inalterados em todos os animais, evidenciando que as fontes protéicas produziram o mesmo efeito em leitões de 36 a 70 dias de idade.

Da mesma forma, Scandolera et al. (2005), trabalhando com dietas contendo leite em pó e isolado protéico de soja para leitões no período de 14 dias após o desmame, também não encontraram diferenças para a morfologia intestinal dos animais. Segundo os autores, as fontes protéicas avaliadas não diminuíram os efeitos deletérios da mudança de alimentação à desmama sobre a morfologia intestinal dos leitões.

Além disso, as mudanças bruscas da morfologia intestinal são observadas duas semanas após o desmame (Cera et al., 1988), por isso, o efeito deletério da proteína foi observado por Li et al. (1991) em leitões recentemente desmamados, mas não foi observado neste experimento. Os leitões utilizados neste trabalho foram desmamados 14 dias antes de serem introduzidos ao experimento e abatidos aos 70 dias de idade, o que poderia culminar, nesta faixa etária, em um sistema digestivo já adaptado às novas dietas. Como não houve efeito dos tratamentos sobre a morfologia intestinal, houve adaptação dos animais ao alimento fornecido.

$\mathrm{O}$ fornecimento da dieta contendo levedura resultou em menor profundidade de cripta, o que indica menor antigenicidade deste ingrediente, uma vez que a profundidade de cripta é indicativo do nível de hiperplasia das células epiteliais, relacionado ao grau de antigenicidade da dieta (Hancock et al., 1990).

O peso de pâncreas/peso de carcaça foi semelhante $(\mathrm{P}>0,05)$ entre as dietas avaliadas (Tabela 5). No entanto, Makkinketal.(1994), em experimento com leitões desmamados aos 28 dias de idade e alimentados com leite em pó desnatado e concentrado protéico de soja, obtiveram peso de pâncreas superior ao dos alimentados com farelo de soja, portanto, a proteína de soja processada apresenta bons resultados de desenvolvimento pancreático nesta fase. $\mathrm{O}$ mesmo foi demonstrado com a inclusão de isolado protéico de soja, que não alterou o desenvolvimento pancreático. 
Tabela 5 - Morfologia intestinal e relação peso do pâncreas/peso da carcaça de leitões alimentados com dietas contendo diferentes níveis e fontes protéicas no período de 36 a 70 dias

\begin{tabular}{lcccccrr}
\hline & \multicolumn{9}{c}{ Fonte protéica* } & \multicolumn{1}{c}{ CV } \\
\cline { 2 - 5 } & LP $(12 \%)$ & LS $(10 \%)$ & IPS $(4,5 \%)$ & FP $(5 \%)$ & IPS $(3,2 \%)$ & LP $(8,8 \%)$ & $(\%)$ \\
\hline Altura de vilos $(\mu \mathrm{m})$ & 312 & 291 & 316 & 396 & 392 & 348 \\
Profundidade de criptas $(\mu \mathrm{m})$ & 154 & 132 & 151 & 169 & 176 & 167 & 30,96 \\
g pâncreas/kg carcaça & 3,19 & 3,23 & 3,24 & 3,19 & 3,40 & 3,40 \\
\hline
\end{tabular}

* LPD - leite em pó desnatado; LS - levedura seca; IPS - isolado protéico de soja; FP - farinha de peixe.

Médias seguidas de mesma letra minúscula (linha) dentro de cada período analisado, não diferem significativamente a $5 \%$ pelo teste Tukey.

Exceto por um período curto após o nascimento e após o desmame, leitões parecem ter capacidade enzimática suficiente para digerir proteínas, amidos e lipídeos a uma taxa tão grande quanto a necessária.

Mudanças no desenvolvimento quantitativo e qualitativo na função pancreática parecem ser uma conseqüência da adaptação à dieta sólida contendo 2 ou 3 vezes mais proteínas e carboidratos que gordura, em comparação ao leite da porca. Assim, o desenvolvimento do pâncreas em suínos depende mais da mudança dietética ao desmame que da idade (Pierzynowki et al., 1993).

\section{Conclusões}

Os níveis e as fontes protéicas estudados não influenciam o desempenho, a morfologia intestinal e a relação do peso de pâncreas e do peso de carcaça em leitões de 36 a 70 dias de idade.

\section{Literatura Citada}

ARAUJO, L.F.; JUNQUEIRA, O.M.; LOPES, E.L. et al. Utilização da levedura desidratada (Saccharomyces cerevisiae) para leitões na fase inicial. Ciência Rural, v.36, p.1576-1581, 2006.

BERTOL, T.M.; LUDKE, J.V.; MORES, N. Efeito de diferentes fontes protéicas sobre desempenho, composição corporal e morfologia intestinal em leitões. Revista Brasileira de Zootecnia, v.29, p.1735-1742, 2000.

CERA, K.R.; MAHAN, D.C.; CROSS, R.F. et al. Effect of age, weaning and postweaning diet on small intestinal growth and jejunal morphology in young swine. Journal of Animal Science, v.66, p.574-584, 1988.

CINQ-MARS, D.; BÉLANGER, G.; LACHANGE, B. et al. Performance of early weaned piglets fed diets containing various amounts of whey protein concentrate. Journal of Animal Science, v.63, p.145-150, 1986.

DEBOER, H.; HACKER, R.R.; LEESON, S. The effects of replacing skim milk powder and/or whey with refined fish protein concentrate (CONMAR 80) in creep and weaner starter diets on pig performance. Canadian Journal of Animal Science, v.68, p.1163-1169, 1988.

HANCOCK, J.D.; PEO JR., E.R.; LEWIS, A.J. et al. Effects of ethanol extraction and heat treatment of soybean flakes on function and morphology of pig intestine. Journal of Animal Science, v.68, p.3244-3251, 1990.

JUNQUEIRA, O.M.; SILZ, L.Z.T.; ARAUJO, L.F. et al. Níveis de substituição do leite em pó desnatado pelo isolado protéico de soja na dieta de leitões desmamados. Revista Brasileira de Zootecnia, v.33, n.6, p.2283-2291, 2004.

LEIBHOLZ, J. Utilization of casein, fish meal and soybean proteins in dry diets for pigs between 7 and 28 of age. Animal Production, v.34, p.9-15, 1982.

LI, D.F.; NELSSEN, J.L.; REDDY, P.G. et al. Measuring suitability of soybean products for early-weaned pigs with immunological criteria. Journal of Animal Science, v.69, p.3299-3307, 1991.

MAKKINK, C.A.; NEGULESCU, G.P.; GUIXIN, Q. et al. Effect of dietary protein source on fee intake, growth, pancreatic enzyme activities and jejunal morphology in newly-weaned piglets British Journal of Nutrition, v.72, p.353-368, 1994.

MOURA, M.P.; FOWLER, V.R. Estudo de rações com diferentes fontes protéicas para leitões desmamados precocemente (três semanas). I. Digestibilidade e performance até $25 \mathrm{~kg}$ de peso vivo. Boletim da Indústria Animal, v.42, p.233-240, 1985.

NABUURS, M.J.A. Microbiological, structural and functional changes of the small intestine of pigs at weaning. Pig News and Information, v.16, p.93N-97N, 1995.

PIERZYNOWSKI, S.G.; WESTRÖM, B.R. ; ERLANSON-ALBERTSSON, C. et al. Induction of exocrine pancreas maturation at weaning in young developing pigs. Journal of Pediatric Gastroenterology and Nutrition, v.16, p.287-293, 1993.

ROBLES, A. Alimentacion del lechon. In: MINI-SIMPÓSIO DO COLÉGIO BRASILEIRO DE NUTRIÇÃO ANIMAL NUTRIÇÃO E ALIMENTAÇÃO DE SUÍNOS, 10., 1993, Campinas. Anais... Campinas: Colégio Brasileiro de Nutrição Amimal, 1993. p.83-89.

STATISTICAL ANALYSIS SYSTEM - SAS. SAS System for Windows: release 6.12. Cary: 1996. (CD-ROM).

SCANDOLERA, A.J.; THOMAZ, M.C.; KRONKA, R.N. et al Efeitos de fontes protéicas na dieta sobre a morfologia intestinal e desenvolvimento pancreático de leitões recém desmamados. Revista Brasileira de Zootecnia, v.34, p.2355-2368, 2005.

STONER, G.R.; ALLEE, G.L.; NELSSEN, J.L. et al. Effect of select menhaden fish meal in starter diets for pigs. Journal of Animal Science, v.68, p.2729-2735, 1990.

THACKER, P.A. Nutritional requirements of early weaned pigs. A review. Pig News and Information, v.20, p.13N-24N, 1999. 